Evaluasi: Jurnal manajemen Pendidikan Islam

ISSN (P): 2580-3387, ISSN (E): 2615-2886

DOI : http://doi.org/10.32478/evaluasi.v5i2.595

Article Type : Original Research Article

\title{
IMPLEMENTASI KURIKULUM DARURAT COVID-19
}

\author{
Didit Haryadi, Fitri Nur Mahmudah \\ Universitas Ahmad Dahlan Yogyakarta, Indonesia
}

Corresponding author: diditharyadi18@gmail.com

Submission Track:

Submisson : : 13-01-2021

Accept Submission : 24-05-2021

Avaliable Online $\quad: 11-09-2021$

Copyright @ 2021 Author

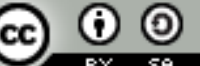

This work is licensed under a Creative Commons Attribution-ShareAlike 4.0

\begin{abstract}
.
The curriculum is at the heart of education. During the Covid pandemic, the government through the ministry of education and culture is working on making the current learning process run well and smoothly even though learning is carried out remotely or online. The latest policy issued by the Ministry of Education and Culture is an emergency curriculum for education units in special conditions. The objectives of the research on the implementation of this emergency curriculum is to knowing the readiness of the school for implementing the emergency curriculum This research uses qualitative research. This research approach is a case study. This research was conducted at SMP PGRI Taropo. Participants in this study were the principal, vice principal in curriculum, and teachers. Data collection techniques using interviews. Data analysis techniques used the Miles Huberman model and were analyzed using the Atlas.ti software version 8. Based on the results of the analysis, the implementation of the emergency curriculum at SMP PGRI Taropo has four important things in its implementation, namely: (1) Teacher Competency Development; (2) Learning Change; (3) Technology Utilization; and (4) Evaluating Learning Outcome
\end{abstract}

Keywords: implementation; emergency curriculum; covid-19 


\begin{abstract}
Abstrak
Kurikulum merupakan jantung dari pendidikan. Pada masa pandemi covid-19 ini pemerintah melalui kementrian pendidikan dan kebudayaan sedang mengupayakan agar proses pembelajaran berjalan dengan baik dan lancar meskipun pembelajaran dilaksanakan secara jarak jauh. Kebijakan terbaru yang dikeluarkan oleh kemendikbud adalah kurikulum darurat pada satuan pendidikan dalam kondisi khusus. Adapun tujuan dari penelitian adalah untuk mengetahui kesiapan sekolah dalam pelaksanaannya. Penelitian ini menggunakan jenis penelitian kualitatif. Pendekatan penelitian ini adalah studi kasus. Penelitian ini dilakukan di SMP PGRI Taropo Partisipan dalam penelitian ini adalah kepala sekolah, wakil kepala sekolah bidang kurikulum, dan guru. Teknik pengambilan data dengan menggunakan wawancara. Teknik analisis data menggunakan model Miles Huberman dan dianalisis dengan berbantuan software Atlas.ti versi 8. Berdasarkan hasil analisis bahwa implementasi kurikulum darurat di SMP PGRI Taropo memiliki empat hal penting dalam pelaksanaannya, yaitu terdiri dari (1) Pengembangan Kompentesi Guru; (2) Learning Change; (3) Pemanfaatan Teknologi; dan (4) Evaluating Learning Outcome
\end{abstract}

Kata Kunci: implementasi; kurikulum Darurat; covid-19

\title{
A. PENDAHULUAN
}

Perubahan dunia pendidikan di tengah Covid-19 masih dirasakan hingga saat ini. Salah satu dampak yang serius dalam pendidikan adalah pembelajaran di rumah. Perubahan ini membutuhkan manajemen yang teratur dan sistematis dari dua belah pihak yaitu sekolah dan orang tua. Karena kondisi ini pemerintah mengeluarkan Surat Edara nomor 4 tahun 2020 tentang pelaksanaan kebijakan pendidikan dalam masa darurat penyebaran corona virus desease (covid-19). Kemenetrian pendidikan dan kebudsyaan pada saat pandemic covid-19 seperti ini tetap melaksanakan pembelajaran walaupun bersifat jarak jauh atau daring. Hal ini dilakukan bertujuan untuk dapat mempertahankan kualitas pendidikan.

Langkah nyata dalam melakukan antisipasi dalam penanggulangan covid-19 ini pemerintah mengeluarkan dua kebijakan baru yaitu perluasan pembelajaran tatap muka untuk zona kuning dan kurikulum darurat. Salah satu kebijakan yang diberikan oleh Kementerian Pendidikan dan Kebudayaan adalah mengeluarkan kurikulum khusus untuk pembelajaran pada masa darurat. Menurut (Mabunga, 2019) kurikulum adalah semua pembelajaran yang dirancang dan dilaksanakan secara individu ataupun secara kelompok baik disekolah maupun diluar sekolah. Begitu juga menurut (Hasbi \& Mahmudah, 2020) bahwa "kurikulum harus dirancang sesuai dengan kondisi dan perkembangan ilmu pengetahun". Hal ini dilakukan supaya alat yang digunakan untuk pembelajaran disusun sesuai kebutuhan di masa pandemi covid-19. Hal itu perlu pemahaman untuk menyusun sehingga guru tidak terpaku pada metode pembelajaran tatap muka. Pelaksanaan kurikulum pada kondisi khusus bertujuan 
untuk memberikan fleksibilitas bagi satuan pendidikan untuk menentukan kurikulum yang sesuai dengan kebutuhan pembelajaran peserta didik.

Kurikulum yang disusun oleh (Pemerintah Indonesia, 2003) memiliki tujuan untuk "mempersiapkan manusia Indonesia agar memiliki kemampuan hidup sebagai pribadi dan warga negara yang beriman, produktif, kreatif, inovatif, dan afektif serta mampu berkontribusi pada kehidupan bermasyarakat, berbangsa, bernegara, dan peradaban dunia". Hal ini senada dengan ayat Al-Quran yang disampaikan pada Q.S. Al-Luqman ayat 17 , bahwa:

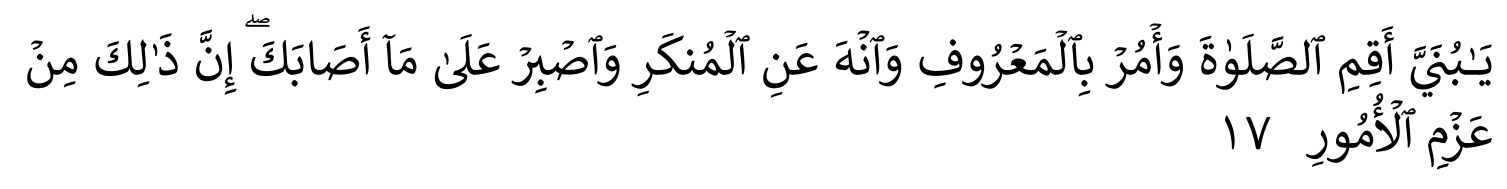

Artinya:

“(Hai anakku, dirikanlah salat dan suruhlah manusia mengerjakan yang baik dan cegahlah mereka dari perbuatan mungkar serta bersabarlah terhadap apa yang menimpa kamu) disebabkan amar makruf dan nahi mungkarmu itu. (Sesungguhnya yang demikian itu) hal yang telah disebutkan itu (termasuk halhal yang ditekankan untuk diamalkan) karena mengingat hal-hal tersebut merupakan hal-hal yang wajib".

Kurikulum Darurat adalah kurikulum yang disusun dan dilaksanakan oleh satuan pendidikan pada masa darurat. Dalam penyusunan kurikulum tetap mengacu pada kurikulum nasional yang sudah ada. Menurut (Taha, Abdalla, \& Wadi, 2020) bahwa:

"the process of curriculum delivery during an pandemi covid-19 emergency has included; establishing a sense of urgency, establishing working teams, conducting needs assessments, developing implementation plans, communicating the curriculum content, capacity building, managing students' stress, finding tools to be used, managing student engagement and motivation, student assessment, anticipating challenges and planning for how to overcome them, and monitoring and evaluation of curriculum implementation and continuous improvement".

Oleh karena itu aspek-aspek yang berhubungan langsung dan tidak langsung dalam penyusunan kurikulum disesuaikan dengan kondisi terkini selama pandemi covid-19. Penyusunan kurikulum darurat tidak merubah total keseluruhan kurikulum nasional. Hal ini membutuhkan keterampilan yang mumpuni untuk modifikasi dan inovasi dalam penyusunannya. Karena tidak merubah isi secara total, melainkan pengurangan kompetensi dasar untuk setiap mata pelajaran sehingga guru dan siswa dapat berfokus pada kompetensi esensial dan kompetensi prasyarat. Menurut (Adam 
et al., 2020) "... an emergency curriculum provides simplification of concepts and learning targets, but it all returns to how professional teachers are in managing learning amid the Covid-19 pandemic". Begitu juga karena menurut (Hamid, Sentryo, \& Hasan, 2020) bahw ".... renewable curriculum and designed with good, dedicated teacher, motivated and equipped with the necessary skills and knowledge".

Kurikulum darurat menjadi bagian integral yang penting untuk tepat dapat digunakan sebagai kesiapan dan alat ukur dalam pembelajaran. Menurut (Daniel, 2020):

"while it is important to continue to orient stu- dents' learning to the classroom curriculum and the assessments/examinations for which they were preparing, it is also vital to maintain students' interest in learning by giving them varied assignments - not least, perhaps, by work that sets the present COVID-19 crisis in a wider global and historical context".

Perubahan kurikulum yang digunakan juga menjadi dasar untuk guru dapat menyesuaikan diri dalam pembelajaran. Salah satunya metode yang digunakan. Hal ini perlu dilakukan karena untuk memastikan pembelajaran tetap berjalan secara efektif dan efisien. (Mohmmed, Khidhir, Nazeer, \& Vijayan, 2020) bahwa "teachers who used to teach live classes will need to engage in novel methods to achieve effective teaching outcomes, which may affect the quality of tertiary education". Berbagai hasil penelitian terdahulu terkait dengan penerapan kurikulum darurat covid-19 yang telah dilakukan dalam penelitian Sanjaya \& Rastini (2020) menjelaskan bahwa upaya dalam pemenuhan hak pendidikan pada masa pandemi covid-19 perlu dilakukan dengan cara menyesuaikan kondisi dengan menggunakan kurikulum darurat covid-19. Hasil penelitian ini meninjau kurikulum darurat dari sudut pandang yuridis. Adapun hasil penelitian lain yang telah dilakukan oleh Munajim, Barnawi, \& Fikriyah (2020) menyatakan bahwa perlunya ruang luas untuk mendesain kembali struktur kurikulum yang dapat digunakan pada masa pandemi covid-19. Penelitian yang telah dilakukan oleh Munajim et.al (2020) tersebut merupakan deskripsi dari hasil-hasil kajian pustaka. Penelitian senada juga dilakukan oleh Yasir, Hamidah, \& Anggia (2020) dalam hasil penelitian yang telah dilakukan mengenai penerapan kurikulum 2013 pada masa pandemi covid-19 perlu ditingkatkan pada tiga aspek yaitu penilaian sikap, pengetahuan dan keterampilan yang mengalami penurunan, sehinga perlu penyesuaian kurikulum.

Berbagai penelitian terdahulu di atas memiliki karakteristik dan substansi yang berbeda dengan penelitian ini. Penelitian ini mengeksplorasi terkait dengan penerapannya yang sudah dilakukan di lapangan oleh sekolah, tentunya yang berkaitan dengan pengembangan kompetensi, pelaksanaan pembelajaran, pemanfaatan teknologi, dan evaluasi yang harus dilakukan. Implementasi kurikulum darurat tidak hanya sekedar menyesuaikan strukturnya saja, melainkan juga substansi dan upaya yang perlu dikembangkan dalam pelaksanaan pembelajaran selama pandemi covid-19. Sehingga pentingnya untuk mengkaji penelitian ini sangat 
diperlukan sebagai bahan temuan baru dalam penerapan kurikulum darurat covid-19. Manfaat yang dapat ditemukan dan disebarluaskan kepada khalayak pada penelitian ini adalah terkait dengan hal-hal efektif yang perlu dilakukan oleh sekolah, guru, dan siswa dalam mengimplementasikan kurikulum ke dalam pembelajaran. Atas dasar pendahuluan tersebut maka penelitian ini bertujuan untuk menggali informasi secara mendalam terkait implementasi kurikulum darurat covid-19.

\section{B. METODE}

Penelitian ini menggunakan jenis penelitian kualitatif. Pendekatan penelitian ini adalah studi kasus. Alasan menggunakan pendekatan studi kasus karena pendekatan studi kasus sangat cocok untuk mengetahui keadaan langsung di lapangan terkait dengan implementasi kurikulum darurat. Penelitian ini dilakukan di SMP PGRI Taropo Partisipan dalam penelitian ini adalah kepala sekolah, wakil kepala sekolah bidang kurikulum, dan guru. Teknik pengambilan data dengan menggunakan wawancara. Teknik analisis data menggunakan model Miles Huberman dan dianalisis dengan berbantuan software Atlas.ti versi 8.

\section{Tabel A.1 Pedoman Wawancara}

\section{Pedoman Wawancara}

1. Bagaimana perencanaan kurikulum darurat covid-19?

2. Apa saja yang perlu diperhatikan dalam implementasi kurikulum darurat covid-19?

3. Faktor apa saja yang mempengaruhi pelaksanaan kurikulum darurat covid-19?

4. Bagaimana kesiapan SMP PGRI Taropo dalam pelaksanaan kurikulum darurat covid-19?

5. Kebijakan apa yang diberikan dalam mendukung implementasi kurikulum darurat?

Prosedur penelitian yang digunakan dalam penelitian ini adalah model interaktif Miles \& Huberman yaitu:

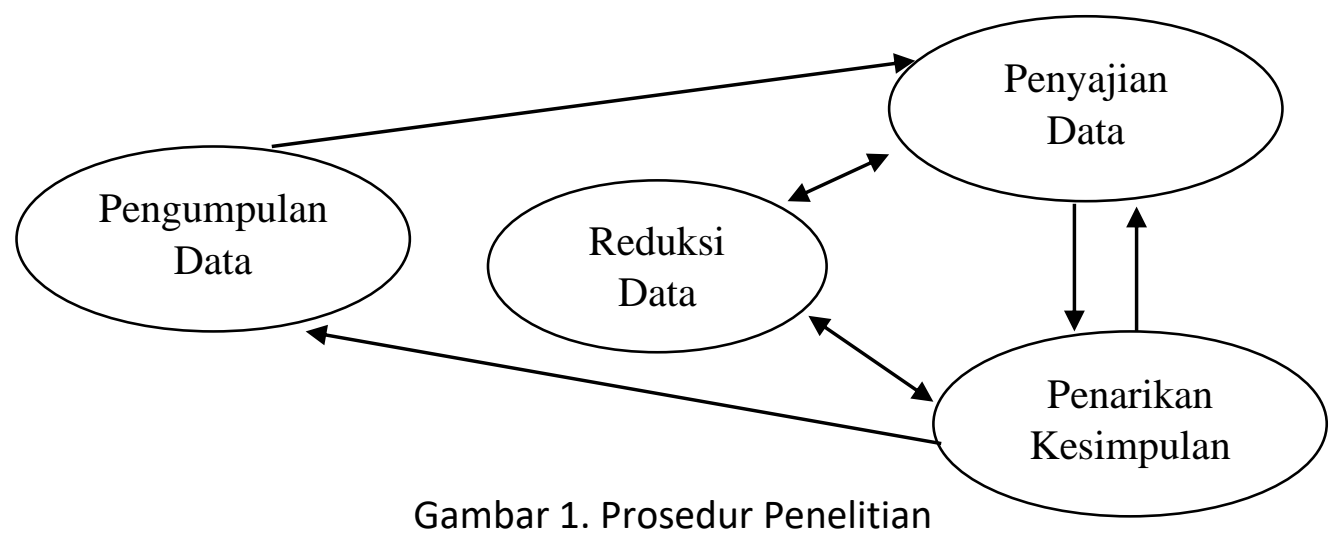

Langkah-langkah dalam penelitian ini dijabarkan sebagai berikut: 
1. Pengumpulan data, peneliti melakukan dengan cara menemui nara sumber lalu menggunakan pedoman wawancara dalam pengambilan data lapangan.

2. Reduksi data, kemudian peneliti melakukan transkrip data dan melakukan analisis untuk sekaligus mencari tema penelitian dan mereduksi data-data yang tidak relevan dengan penelitian ini. Langkah ini menggunakan software Atlas.ti versi 8

3. Penyajian data, data-data yang sudah direduksi kemudian dicari tema besar dari penelitian kemudia disajikan ke dalam model analisis.

4. Penarikan kesimpulan, Akhir dari penelitian adalah memberikan pembahasan dan kesimpulan terhadap substansi dari implementasi kurikulum darurat covid-19

\section{HASIL DAN PEMBAHASAN}

Penelitian ini melibatkan tiga sumber data yang memahami kondisi kurikulum yang ada di SMP PGRI Taropo. Kurikulum menjadi bagian penting dalam menjalankan proses pendidikan. Termasuk dalam kondisi pandemi covid-19 ini. Menurut Sepa/W/1, bahwa:

"kita sosialisasikan dengan cara kita mengundang bapak/ibu wali murid dan komite adakan rapat sosialisasi hasil kesepakatan bapak/ibu guru dengan adanya pembelajaran jarak jauh atau PJJ yang menggunakan kurikulum darurat ini"

Hal-hal yang perlu diperhatikan dalam implementasi kurikulum darurat menurut Urak/W/2 dan Ruga/W/3 dapat dinyatakan bahwa:

"hal-hal yang perlu dipertimbangkan. Yang pertama kesiapan guru, dalam arti bapak/ibu guru harus paham dengan model-model pembelajaran yang akan diterapkan nanti yang mudah di pahami oleh siswa. Yang kedua finansial ya, ini yang perlu dipertimbangkan antaralain jenis hp yang digunakan dan pulsa antara lain hal-hal yang perlu kami persiapkan dan mempertimbangkan dalam pelaksanaan kurikulum darurat ini. analisis kebutuhan itu sangat perlu dilakukan sehingga pada sekolah kami, yang pertama kesiapan bapak/ibu guru untuk meluangkan waktunya, yang kedua biaya pulsa bagi guru dan siswa kita sudah analisis. Berbulanya Minimal berapa untuk guru dan berapa untuk siswa. Alhamdulilah untuk dana bos yang kemarin kita terapkan hal itu.bapak/ibu guru kita mengisi paket yang 50 ribu sedangkan siswa masing-masing 25 ribu" 
Pada saat implementasi, banyak faktor yang mempengaruhi terkait pelaksanaan kurikulum darurat covid-19, apalagi dengan kondisi yang serba mendadak. Hal ini disampaikan oleh Urak/W/2, bahwa:

"dari faktor pendukung kalo dilihat antusiasi siswa lumayan mereka walaupun dalam keadaan darurat covid mereka ini masih mau dan dukungan juga dari faktor dari orang tua walaupun mereka karna kita daerah trasmigrasi anggaplah siswa memiliki orang tua yang berpendidikan rendah makanya posisinya seperti itu jadi mereka selalu mendukung anaknya faktor pendukung orang tua makanya selalu belajar untuk keterbatasnya. sebenarnya dijelasin satu persatu itu banyak tapi hambatannya namanya juga kita berada di daerah pinggiran jadi hambatanya sangat banyak termaksud siswa kita belum punya gadjet dalam melaksanakan kegiatan ini adanya hambatan"

Pernyataan di atas juga ditegaskan oleh Sepa/W/1, yang menyatakan bahwa:

"kesiapan guru untuk menerima kurikulum darurat tersebut, walaupun penuh dengan kekhawatiran karena pada awalnya mereka tidak tahu yang semestinya seperti apa kurikulum ini. ada beberapa guru mapel yang memiliki kemampuan IT yang semestinya semua mapel itu kita utus namun karena beberapa guru mapel yang mampu menggunakan IT yang sebenarnya kita melakukan mengirim untuk mengikuti diklat atau workshop yang antara lain kemarin adalah salah satu googleclassrom. Hambatanya cukup luar biasa, yang pertama siswa jenis hp yang digunakan tidak semua hp canggih atau hp pintar atau android mayoritas yang digunakan siswa ini hp kecil atau hp jadul, sehingga kita hambatan tersebut kita melakukan pemetaan dengan catatat kita membagi kelompok yang misalnya 4 kelompok kita ubah jadi 2 kelompok karena hanya $2 \mathrm{hp}$ android yang dimiliki siswa. Yang kedua jarak tempat tinggal siswa jadi susah, yang ketiga jaringanya kadang jaringanya lemah, yang berikutnya pemahaman siswa terkait pembelajaran. Menggunakan daring ini belum sepenuhnya beda dengan tatap muka, jadi respon siswa dengan tatap muka dengan dari ini jauh bedanya untuk menanggapi dan merespon atau memahami yang di sampaikan oleh bapak ibu guru"

Implementasi kurikulum darurat covid-19 juga melihat terkait dengan kesiapan warga sekolah dalam melaksanakannya, data lapangan menurut Sepa/W/1 mengatakan bahwa:

"kesiapan guru untuk menerima kurikulum darurat tersebut, walaupun penuh dengan kekhawatiran karena pada awalnya mereka tidak tahu yang semestinya seperti apa kurikulum ini yang antara lain siswa kita antisipasi ini beberapa kelas dibagi menjadi beberapa kelompok. Yang kedua atau berikutnya guru kita 
coba untuk memandu sebuah kelompok guru atau tim teacher yang selalu mengadakan kolaboratif antara sesama guru bidang studi yang ada"

Pernyataan di atas juga didukung oleh pernyataan nara sumber lain yaitu dari Ruga/3/W bahwa "sudah sosialisasikan oleh semua guru yang ada disini. Dan semua wali murid sudah di undang untuk mensosialisasikan sekolah ini terkait dengan penerapan kurikulum darurat" Begitu juga menurut Urak/W/2 yang menyatakan bahwa:

"kemarin itu kita juga saya sebagai wakasek kurikulum untuk melakukan pelatihan tentang bagaimana cara kita menjalankan kurikulum darurat ini, jadi kemarin melakukan pelatihan khususnya jadi kita ini supaya apa dan siswa ini tidak berhenti belajar jadi sekolah untuk mewakilkan saya untuk melakukan studi-studi di sekolah lain yang harus di persiapkan siswanya yang seperti kemarin kita mencoba memberikan karna sebelumnya pada bantuan untuk kuota dan yang kedua KBM kita memakai KBM luring jadi memberikan bantuan kepada guru berupa paket buat belajar mengajar"

Kebijakan yang diberikan dalam mendukung implementasi kurikulum darurat covid-19 menurut nara sumber Sepa/W/1 adalah sebagai berikut:

"untuk disekolah kami. Saya sebagai kepala sekolah mengambil suatu kebijakan yang pertama. Semua stakeholder atau warga sekolah diantara lain segenap bapak/ibu guru akan berusaha dll. Kita melakukan rapat koordinasi dengan adanya kurikulum darurat ditengah covid 19 ini sehingga menawarkan ataupun kita memperkenalkan 3 opsi, yang pertama tetap mengacu pada kurikulum nasional, yang kedua menggunakan kurikulum darurat yang ketiga melakukan penyederhanaan kurikulum secara mandiri. Jadi 3 point itu yang kami perkenalkan kepada semua warga yang ada disekolah ini.

Begitu juga menurut Urak/2/W yang menyatakan bahwa "kepala sekolah sangat mendukung semua guru disini baik secara memberikan penerapan penerapan tentang kurikulum darurta ini di lakukan, kebijakan nya sengat bagus menurut saya, sekolah kita juga dari kepalah sekolah sangat mendukung kita semua disini, lebih lebih guru guru disini Alhamdulillah kebijakan kepalah sekolah sangatlah baik". Hal ini juga disampaikan oleh Ruga/3/W yang memberikan pernyataan bahwa:

"baik terimakasih, saya menjelaskan sedikit tentang penerapan kebijakan kepala sekolah, kepala sekolah itu kemarin dengan wali murid melakukan rapat bagai mana cara menerapkan kurikulum sebenarnya kurikulum yang disederhanakan dan tidak diberi arahan apa yang harus dilakukan sebaginya jadi kepala sekolah itu sangat respek apa yang harus dilakukan maupun dan 
selalu dalam perbaikan KBM mau berupa KBM tatap muka luring maupun KBM daring"

Berdasarkan data-data lapangan yang sudah dikumpulkan di atas, selanjutnya data-data yang terkumpul dianalisis dengan menggunakan software berbantuan Atlas.ti versi 8. Gambar 1 merupakan hasil analisis data kualitatif impelementasi kurikulum darurat covid-19.

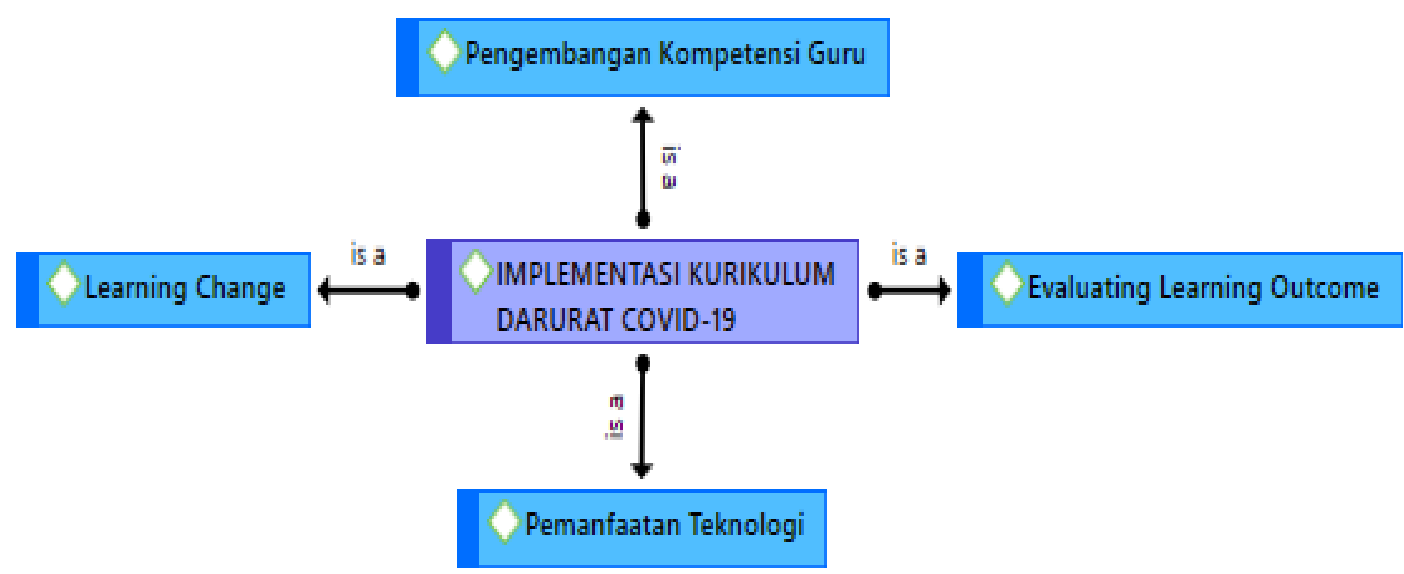

Gambar 2. Hasil Analisis Data Implementasi Kurikulum Darurat Berbantuan Software

Berdasarkan hasil analisis pada gambar 1, bahwa implementasi kurikulum darurat di SMP PGRI Taropo memiliki empat hal penting dalam pelaksanaannya, yaitu terdiri dari (1) Pengembangan Kompentesi Guru; (2) Learning Change; (3) Pemanfaatan Teknologi; dan (4) Evaluating Learning Outcome. Perubahan kurikulum darurat covid-19 tentunya dapat diterapkan dengan mempertimbangkan hal-hal penting yang ada dalam teori pengembangan kurikulum. Hal ini sesuai dengan teori pengembangan kurikulum menurut Arifin (2011) bahwa perubahan kurikulum dilakukan karena beberapa karakteristik salah satunya adalah karena mendampilan pandangan yang jelas dan sistemik mengenai suatu fenomena. Hal senada juga disampaikan oleh Muhaimin (2005: 10) yang menyatakan bahwa perubahan kurikulum sama halnya melakukan pengembangan kurikulum dimana kegiatan yang dilakukan menghasilkan kurikulum proses yang mengaitkan satu komponen dengan yang lainnya untuk menghasilkan kurikulum yang lebih baik sesuai dengan kondisi saat ini. Oleh karena itu pengembangan kurikulum dalam penerapan kurikulum darurat covid-19 ini juga mempertimbangkan aspek-aspek pendukung dalam pelaksanaannya. Berdasarkan hasil analisis yang sudah dilakukan, masing-masing komponen penting dari temuan hasil penelitian ini akan dibahas sebagai berikut: 


\section{Pengembangan Kompentensi Guru}

Pengembangan kompetensi guru merupakan aktivitas untuk menunjang profesionalisme guru agar memiliki kompetensi profesi, yaitu agar mampu melaksanakan tugas pokok dan kewajiban dalam melaksanakan proses pembelajaran/pembimbingan, termasuk pelaksanaan tugas tambahan yang relevan dengan fungsi sekolah (Sutikno, 2011). Kompetensi merupakan perpaduan dari pengetahuan, ketrampilan, nilai dan sikap yang direfleksikan dalam kebiasaan berpikir dan bertindak (Pend et al., 2015). Sedangkan menurut (Musa, 2016) Kompetensi adalah seperangkat pengetahuan, ketrampilan, dan prilaku yang harus dimiliki, dihayati, dan dikuasai oleh guru/dosen dalam menjalankan tugas keprofesionalannya. Dari pendapat pendapat yang sudah dijelaskan disimpulkan bahwa Pengembangan Kompetensi guru adalah suatu aktivitas yang dilakukan oleh guru untuk menjadikan memiliki keterampilan, nilai dan sikap yang baik saat menjalankan tugas.

Pengembangan kompetensi guru dalam makna manajemen pendidikan islam, dapat dipahami di dalam Al-Quran Surat Al'Imran ayat 152:

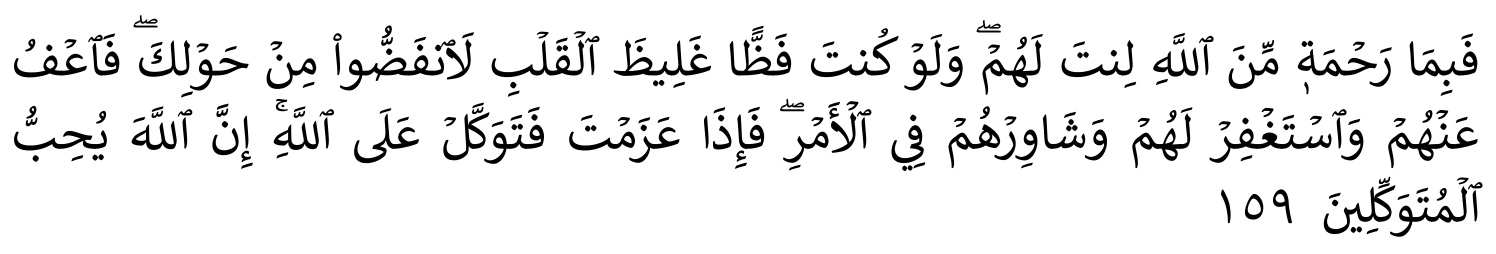

Artinya:

"(Maka berkat) merupakan tambahan (rahmat dari Allah kamu menjadi lemah lembut) hai Muhammad (kepada mereka) sehingga kamu hadapi pelanggaran mereka terhadap perintahmu itu dengan sikap lunak (dan sekiranya kamu bersikap keras) artinya akhlakmu jelek tidak terpuji (dan berhati kasar) hingga kamu mengambil tindakan keras terhadap mereka (tentulah mereka akan menjauhkan diri dari sekelilingmu, maka maafkanlah mereka) atas kesalahan yang mereka perbuat (dan mintakanlah ampunan bagi mereka) atas kesalahankesalahan itu hingga Kuampuni (serta berundinglah dengan mereka) artinya mintalah pendapat atau buah pikiran mereka (mengenai urusan itu) yakni urusan peperangan dan lain-lain demi mengambil hati mereka, dan agar umat meniru sunah dan jejak langkahmu, maka Rasulullah saw. banyak bermusyawarah dengan mereka. (Kemudian apabila kamu telah berketetapan hati) untuk melaksanakan apa yang kamu kehendaki setelah bermusyawarah itu (maka bertawakallah kepada Allah) artinya percayalah kepada-Nya. (Sesungguhnya Allah menyukai orang-orang yang bertawakal) kepada-Nya." 
Pengembangan kompetensi guru dalam penyusunan kurikulum darurat menjadi bagian penting. Guru dapat memahami kondisi dan karakteristik serta mampu memberikan pemahaman pada guru yang lain untuk menyiapkan diri dalam metode yang berbeda selama pandemi covid-19. Pengembangan kompetensi guru masa pandemi covid-19 merupakan langkah yang tepat untuk beradaptasi dengan kondisi yang berbeda. Tuntutan guru dalam penyesuaian ini meliputi cara pemanfaatan teknologi dalam pembelajaran, mampu mengoperasikan peralatan yang menjadi alat pembelajaran, mampu menyusun materi pembelajaran yang menarik, inovatif, tidak monoton, dan sesuai dengan relevansi tujuan dari mata pelajaran yang telah ditetapkan. Hal ini menjadi poin penting karena guru adalah pusat pendidikan yang utama di sekolah. Seperti yang disampaikan oleh (Prasojo, Mukminin, \& Mahmudah, 2017) bahwa "guru merupakan sumber daya manusia yang membutuhkan pengembangan diri sebagai upaya dalam kemajuan pendidikan". Pengembangan guru ini adalah usaha sadar yang terus menerus sehingga guru memiliki sikap yang dibutuhkan oleh siswa saat proses pembelajaran selama masa covid-19 dan dengan cara jarak jauh.

\section{Learning Change}

Perkembangan era menuntut guru untuk mampu menyesuaikan diri. Pendidikan telah berkembang dari metode pembelajaran yang tradisional dan menjadi menggunakan teknologi. "Di era milennial ini tantangan guru semakin kompleks" (Wasehudin, 2018). Dengan itu "learning innovations should ideally be developed according to technological development" (Syakdiyah, Mahmudah, \& Wiwik, 2019). Kemajuan teknologi informasi dan komunikasi (TIK) telah memicu perubahan signifikan di semua jenjang pendidikan, mulai dari taman kanak-kanak hingga perguruan tinggi (Shadiev et al., 2018). Menurut (Devincenzo, 2020) bahwa mengajar di era digital tidak lagi bercerita, dan belajar tidak lagi mendengarkan. Hal yang sama dinyatakan oleh (Chaeruman, 2020) bahwa lingkungan belajar yang ideal untuk pelajar digital adalah lingkungan belajar yang kaya yang memungkinkan dan mendukung pelajar untuk belajar secara mandiri dan kolaboratif.

Perubahan dalam pembelajaran merupakan dasar untuk kemajuan pendidikan. Era dimana pendidikan mampu beradaptasi dalam situasi dan kondisi. Materi, metode, dan media yang digunakan menjadi pertimbangan dalam learning change. Perubahan dalam pembelajaran merupakan kompetisi. Menurut (Mahmudah \& Cahya, 2020) bahwa "learning change need the teacher improvement and have skills more". Pernyataan tersebut didukung oleh (Vare \& Scott, 2007) bahwa "learning is a tool to facilitate choice between alternative futures which can be specified on the basis of what is known in the present". Hal senada juga disampaikan oleh (Burner, 2018) bahwa "the idea is very much in line with student-centred learning, taking diversity seriously by respecting and acknowl- edging the strengths of every student". Di dalam 
Alquran juga sudah dijelaskan betapa pentingnya learning change, yaitu pada Surat An-Nahl ayat 125:

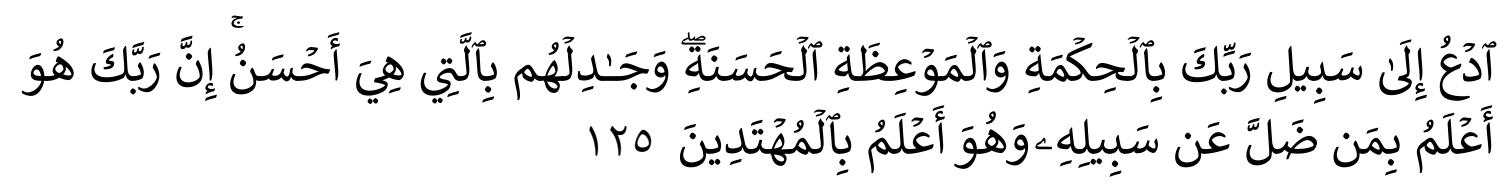

Artinya:

"(Serulah) manusia, hai Muhammad (kepada jalan Rabbmu) yakni agama-Nya (dengan hikmah) dengan Alquran (dan pelajaran yang baik) pelajaran yang baik atau nasihat yang lembut (dan bantahlah mereka dengan cara) bantahan (yang baik) seperti menyeru mereka untuk menyembah Allah dengan menampilkan kepada mereka tanda-tanda kebesaran-Nya atau dengan hujah-hujah yang jelas. (Sesungguhnya Rabbmu Dialah Yang lebih mengetahui) Maha Mengetahui (tentang siapa yang tersesat dari jalan-Nya dan Dialah yang lebih mengetahui orang-orang yang mendapat petunjuk) maka Dia membalas mereka; ayat ini diturunkan sebelum diperintahkan untuk memerangi orangorang kafir. Dan diturunkan ketika Hamzah gugur dalam keadaan tercincang; ketika Nabi saw. melihat keadaan jenazahnya, lalu beliau saw. bersumpah melalui sabdanya, "Sungguh aku bersumpah akan membalas tujuh puluh orang dari mereka sebagai penggantimu."

\section{Pemanfaatan Teknologi}

Pemanfaatan teknologi informasi pada era digital ini sudah seharusnya dilakukan oleh semua kalangan. Sesuai dengan Undang - Undang Republik Indonesia nomor 11 tahun 2008 tentang pemanfaatan teknologi informasi dan transaksi elektronik dilaksanakan berdasarkan asas kepastian hukum, manfaat, kehati-hatian, itikad baik dan kebebasan memilih teknologi atau netral teknologi. Tujuan ini menegaskan bahwa pemanfaatan teknologi informasi dan komunikasi merupakan langkah konkrit untuk memajukan bangsa dimana kemajuan tersebut dapat dicapai apabila seluruh kalangan masyarakat secara aktif menggunakan teknologi informasi dan komunikasi secara efektif dan efisien. Menurut (Kurniawan \& Mahmudah, 2020) bahwa "the learning process is inseperable from the application of information and communication technology in order to maintain the quality of learning." Begitu juga menurut (Mahmudah, Yulianto, \& Nafia, 2020) bahwa "tujuan ini menjadi lebih bermanfaat dikarenakan guru yang ada masih harus mengembangkan diri dalam pengoperasian dan pemanfaatan teknologi terkini untuk menunjang kelancaran pembelajaran". Menurut (Mutia, 2007) "teknologi merupakan pengembangan dan aplikasi dari alat, mesin, material, dan proses yang membantu gur dalam menyelesaikan masalah pada saat proses pembelajaran". 
Allah telah menggambarkan tentang teknologi di dalam Alquran yaitu Surat AlAnbiya ayat 80-81, yaitu:

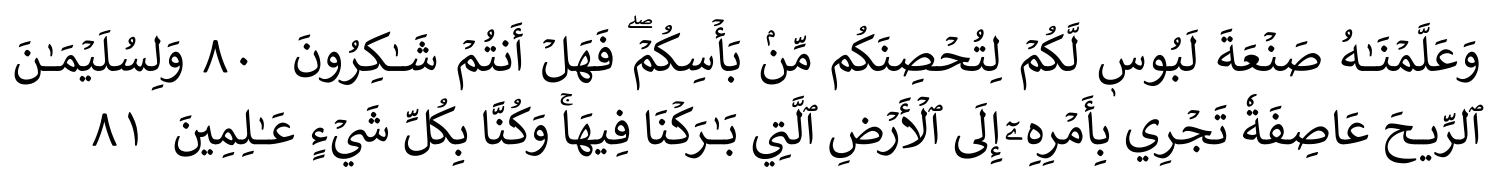

Artinya:

(Dan Kami ajarkan kepada Daud membuat baju besi) yaitu baju yang terbuat dari besi, dialah orang pertama yang menciptakannya dan sebelumnya hanyalah berupa lempengan-lempengan besi saja (untuk kalian) yakni untuk segolongan manusia (guna melindungi diri kalian) jika dibaca Linuhshinakum, maka Dhamirnya kembali kepada Allah, maksudnya, supaya Kami melindungi kalian. Dan jika ia dibaca Lituhshinahum, maka Dhamirnya kembali kepada baju besi, maksudnya, supaya baju besi itu melindungi diri kalian. Jika dibaca Liyuhshinakum, maka Dhamirnya kembali kepada Nabi Daud, maksudnya, supaya dia melindungi kalian (dalam peperangan kalian) melawan musuhmusuh kalian. (Maka hendaklah kalian) hai penduduk Mekah (bersyukur) atas nikmat karunia-Ku itu, yaitu dengan percaya kepada Rasulullah. Maksudnya bersyukurlah kalian atas hal tersebut kepada-Ku. (80)

(Dan) telah Kami tundukkan (untuk Sulaiman angin yang sangat kencang tiupannya) dan pada ayat yang lain disebutkan Rukha-an, artinya angin yang sangat kencang dan pelan tiupannya, kesemuanya itu sesuai dengan kehendak Nabi Sulaiman (yang berhembus dengan perintahnya ke negeri yang kami telah memberkatinya) yakni negeri Syam. (Dan adalah Kami Maha Mengetahui segala sesuatu) antara lain ilmu Allah yang telah diberikan kepada Sulaiman itu akan mendorongnya tunduk patuh kepada Rabbnya. Allah melakukan hal itu sesuai dengan ilmu-Nya yang maha mengetahui segala sesuatu. (81)"

\section{Evaluating Learning Outcome}

Evaluasi merupakan alat ukur yang dapat digunakan untuk melihat seberapa besar keberhasilan dalam pembelajaran. Langkah ini dilakukan disetiap akhir kegiatan. Tujuannya adalah untuk melakukan penilaian proses dan merencanakan kegiatan selanjutnya. Program evaluasi ini memang perlu dilakukan untuk dapat meniingkatkan output dari pembelajaran. Tanpa ada evaluasi, guru tidak dapat memahami kemajuan siswa. Menurut (Elistanto \& Mahmudah, 2020) bahwa "evaluasi yang baik tanpa didukung oleh tindak lanjut yang baik pula, maka sulit untuk meningkatkan kualitas dan mutu pendidikan yang mutakhir". Perlunya panduan untuk melakukan evaluasi terhadap hasil dari pembelajaran. Hal ini menjadi tugas seorang 
guru untuk menyamakan persepsi terkait dengan evaluasi. Menurut (ICARE Project, 2020) bahwa "guidelines for evaluations suggest to use a portfolio - 'an organised collection of materials that presents and verifies skills and knowledge acquired through experience". Oleh karena itu pentingnya untuk menyiapkan formulir yang digunakan sebagai evaluasi dan kisi-kisi terkait dari materi pembelajaran, metode yang digunakan, dan informasi lainnya untuk dapat dijadikan sebagai bahan kajian. Hal ini ditegaskan oleh (Nachouki, 2017) bahwa "evaluations as indirect assessment instruments in addition to the internship survey forms".

Evaluasi pembelajaran juga dijelaskan di dalam Alqur'an yaitu Al-Ankabut ayat

2-3:

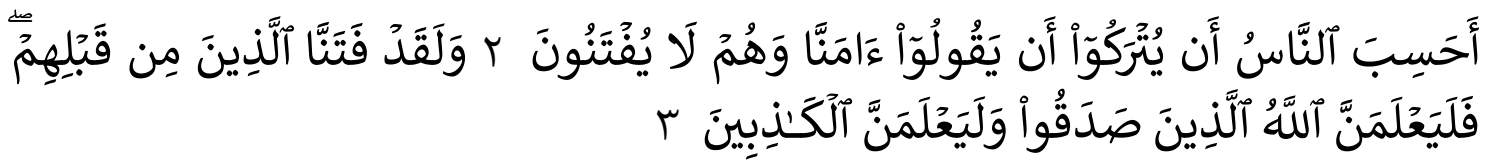

Artinya:

(Apakah manusia itu mengira bahwa mereka dibiarkan saja mengatakan) mengenai ucapan mereka yang mengatakan, ("Kami telah beriman", sedangkan mereka tidak diuji lagi?) diuji lebih dulu dengan hal-hal yang akan menampakkan hakikat keimanan mereka. Ayat ini diturunkan berkenaan dengan orang-orang yang masuk Islam, kemudian mereka disiksa oleh orangorang musyrik. (2)

(Dan sesungguhnya Kami telah menguji orang-orang yang sebelum mereka. Sesungguhnya Allah mengetahui orang-orang yang benar) di dalam keimanan mereka dengan pengetahuan yang menyaksikan (dan sesungguhnya Dia mengetahui orang-orang yang dusta) di dalam keimanannya. (3)

\section{KESIMPULAN}

Berdasarkan hasil penelitian dan pembahasan maka dapat disimpulkan bahwa SMP PGRI Taropo mempersiapkan kurikulum darurat covid-19 dengan secara sistematis mulai dari perencanaan, evaluasi, hingga kebijakan yang diperlukan dalam implementasinya. SMP PGRI Taropo menjadi bagian yang ikut andil dalam menjalan kebijakan kurikulum darurat covid-19. Hal ini dilakukan untuk dapat mempertahankan pembelajaran walaupun dalam kondisi yang kurang maksimal dan kurang memungkinkan untuk dilakukannya secara tatap muka. Memperhatikan kondisi yang seperti ini, SMP PGRI Taropo memanfaatkan yang ada untuk menjaga kualitas pendidikan dan memperhatikan kondisi siswa-siswa dalam proses pembelajaran. 
Pelaksanaan pembelajaran tetap dilakukan karena ini menyangkut pengembangan siswa dalam memahami materi pembelajaran, menambah wawasan, dan tidak meluangkan kesempatan untuk berhenti belajar. Temuan dari penelitian ini memberikan informasi bahwa dalam implementasi kurikulum darurat covid-19 memiliki faktor penting yaitu pengembangan kompetensi guru, learning change, pemanfaatan teknologi, dan evaluating learning outcomes selama proses pembelajaran disaat pandemi covid-19.

\section{REFERENSI}

Arifin, Zainal. (2011) Konsep dan Model Pengembangan Kurikulum. Bandung: Remaja Rosdakarya

Adam, A., Oja, R., Timan, A., Kholilurrokhman, D., Rahmawati, D. R., Eny, D., \& Faiza, N. (2020). Curriculum of the industry revolution 4.0 and the pandemic of covid19 era. !st International Conference on Information Technology and Education, 508(Icite), 332-337.

Burner, T. (2018). Why is educational change so difficult and how can we make it more effective ? Original Research, 1(1), 122-134.

Chaeruman, U. A. (2020). Ruang Belajar Baru Dan Implikasi Terhadap Pembelajaran Di Era Tatanan Baru. Kwangsan: Jurnal Teknologi Pendidikan, 8(1), 142. https://doi.org/10.31800/jtp.kw.v8n1.p142--153

Daniel, S. J. (2020). Education and the COVID-19 pandemic. PROSPECTS, 1(4), 1-6. https://doi.org/10.1007/s11125-020-09464-3

Devincenzo, J. L. (2020). CLIMATE CHANGE AND COGNITION: TOWARDS A PEDAGOGY.: EBSCOhost, 73(1), 69-86.

Elistanto, R., \& Mahmudah, F. (2020). Evaluasi Efektivitas Manajemen Pembelajaran Guru Produktif Otomotif SMK. Jurnal Studi Manajemen Pendidikan, 4(1), 102115.

Hamid, R., Sentryo, I., \& Hasan, S. (2020). Online learning and its problems in the Covid-19 emergency period. Jurnal Prima Edukasia, 8(1), 86-95.

Hasbi, R. P., \& Mahmudah, F. N. (2020). Pengembangan kurikulum sekolah. Nidhomul Haq: Jurnal Manajemen Pendidikan Islam, 5(2), 1-6. https://doi.org/10.31538/ndh.v5i2.563

ICARE Project. (2020). Learning outcomes evaluation. Europe.

Kurniawan, A., \& Mahmudah, F. N. (2020). Implementation of Learning in Vocational School. Al-Tanzim: Jurnal Manajemen Pendidikan Islam, 4(2), 184-196. 
Mabunga, M. (2019). Pengembangan Kurikulum dalam Pembelajaran Contents Abad $\mathrm{XXI}, M(2), 103-112$.

Mahmudah, F. N., \& Cahya, E. (2020). What Makes Employees Productive and Have High Performance ? Human Capital Investment in Universities. Asian Journal of Education and Social Studies, 11(1), 21-36. https://doi.org/10.9734/AJESS/2020/v11i130281

Mahmudah, F. N., Yulianto, D., \& Nafia, Z. I. (2020). Penerapan program literasi digital melalui computational thinking dalam pembelajaran. Seminar Nasional Hasil Pengabdian Kepada Masyarakat, 1(November), 327-338.

Mohmmed, A. O., Khidhir, B. A., Nazeer, A., \& Vijayan, V. J. (2020). Emergency remote teaching during Coronavirus pandemic : the current trend and future directive at Middle East College Oman. Innovative Infrastructure Solutions, 5(3), 1-11. https://doi.org/10.1007/s41062-020-00326-7

Muhaimin. (2005). Pengembangan kurikulum pendidikan agama islam di sekolah, madrasah, dan perguruan tinggi. Jakarta: Rajagrafindo Persada

Munajim, Ahmad, Barnawi, \& Fikriyah (2020). Pengembangan Kurikulum Pembelajaran di Masa Darurat. DWIJA CENDEKIA: Jurnal Riset Pedagogik, 4(2), 285-291. https: //jurnal.uns.ac.id/jdc

Musa, M. I. (2016). No Title, 2(4), 8-27.

Mutia. (2007). Teknologi dalam alquran. Islam Futura, VI(2), 70-77.

Nachouki, M. (2017). Assessing and evaluating learning outcomes of the information systems program. World Journal of Educational Research, 4(4), 2-14. https://doi.org/10.22158/wjer.v4n4p524

Pemerintah Indonesia. Undang-undang republik indonesia nomor 20 tahun 2003 tentang sistem pendidikan nasional (2003). Jakarta Indonesia.

Pend, J., Mesin, T., Universitas, F. T., Yogyakarta, N., Email, I., Pendidikan, P., \& Jepang, K. (2015). Syukri Fathudin Achmad Widodo.

Prasojo, L. D., Mukminin, A., \& Mahmudah, F. N. (2017). Manajemen strategi human capital dalam pendidikan. Yogyakarta: UNY Press.

Sanjaya JB \& Rastini (2020). Implementasi kurikulum darurat di masa pandemi covid19 dalam upaya pemenuhan hak pendidikan. Journal of Indonesian Law, 1(2), 161-174. https://e-journal.iainsalatiga.ac.id/index.php/jil/index

Shadiev, R., Hwang, W., Chen, N., Huang, Y., Shadiev, R., Hwang, W., ... Huang, Y. (2018). International Forum of Educational Technology \& Society Review of Speech-to-Text Recognition Technology for Enhancing Learning Published by : International Forum of Educational Technology \& Society Linked references are 
available on JSTOR for this article. International Forum of Educational Technology \& Society Are, 17(4), 65-84.

Sutikno, A. (2011). UPAYA PENINGKATAN KOMPETENSI GURU, (1), 45-57.

Syakdiyah, A., Mahmudah, N. F., \& Wiwik, W. (2019). Active Learner Strategies in Era of Disruption : a Literature Review. International Conference on Progressive Civil Society, 317(1), 165-168.

Taha, M. H., Abdalla, M. E., \& Wadi, M. (2020). Curriculum delivery in Medical Education during an emergency: a guide based on the responses to the COVID-19 pandemic. MedEdPublish, 1(4), 1-13. https://doi.org/10.15694/mep.2020.000069.1

Vare, P., \& Scott, W. (2007). Learning for a change: exploring the relationship between education and sustainable development. Journal of Education for Sustainable Development, 1(2), 191-198. https://doi.org/10.1177/097340820700100209

Wasehudin. (2018). Perspektif alquran dan undang-undang tentang guru profesional. RARBAWI: Indonesian Journal of Islamic Education, 5(1), 111-122.

Yasir S, Hamidah, \& Anggia PD (2020) Penerapan kurikulum 2013 pada masa pandemi covid-19 di SMP IT Ad-Durrah Medan. Jurnal Pendidikan Islam, 1(3), 233-247. https:// 0.30596/al-ulum.v\%vi\%i.82 